\title{
COMPARISON OF DIRECT IMMUNOFLUORESCENCE, IODINE-SALINE WET MOUNT AND MODIFIED ACID FAST STAINING METHODS FOR DETECTION OF CRYPTOSPORIDIUM AND GIARDIA SPP. IN HUMAN FECAL SPECIMENS
}

Prakriti Vohra, Pooja Singla, Madhu Sharma, Aparna Yadav, Uma Chaudhary

1. Senior Resident, Department of Microbiology, Pt. B. D. Sharma, PGIMS, Rohtak.

2. Senior Resident, Department of Microbiology, Pt. B. D. Sharma, PGIMS, Rohtak.

3. Professor, Department of Microbiology, Pt. B. D. Sharma, PGIMS, Rohtak.

4. Professor, Department of Microbiology, Pt. B. D. Sharma, PGIMS, Rohtak.

5. Senior Professor \& Head, Department of Microbiology, Pt. B. D. Sharma, PGIMS, Rohtak.

\section{CORRESPONDING AUTHOR}

Prakriti Vohra,

Senior Demonstrator,

Department of Microbiology,

Pt. B. D. Sharma, PGIMS, Rohtak.

E-mail: prakriti@yahoo.com,

Ph: 91-9992289955.

ABSTRACT: BACKGROUND: Cryptosporidiosis and Giardiasis are leading causes of parasitic intestinal diseases. There are various methods to detect them including iodine-saline wet mount for Giardia, Modified Acid fast (MAF) staining for Cryptosporidia and Direct Fluorescent Antigen detection (DFA) method._OBJECTIVES: This study was conducted to compare three methods for the detection of_Cryptosporidium oocysts and Giardia cysts in fecal samples._METHOD: 44 stool specimens from patients with history of diarrhea were examined for Giardia lamblia and Cryptosporidium parvum by using a direct immunofluorescent-monoclonal antibody stain (for unspun specimens), Iodine- saline wet mount method for Giardia cysts \& trophozoites and Modified acid-fast for Cryptosporidium oocysts._RESULTS: From the total of 44 specimens; 29 (65.9\%) Cryptosporidia oocysts were isolated and 6 (13.6\%) Giardia cysts by all the IodineSaline wet mount, MAF, DFA methods. The direct immunofluorescent-monoclonal antibody method resulted in a significantly increased detection of both Giardia cysts (5 versus 1 specimens, $\mathrm{p}$ value $=0.01$ ) and Cryptosporidium oocysts (19 versus 10 specimens, $\mathrm{p}$ value=0.01)._CONCLUSIONS: DFA is a sensitive method for detection of Cryptosporidium oocysts and Giardia cysts in fecal samples whereas MAF is a reliable screening method.

KEY WORDS: Cryptosporidium, Giardia, DFA, Modified Acid-fast Staining.

INTRODUCTION: Cryptosporidiosis and Giardiasis are two of the most commonly seen protozoal causes of diarrhea. Outbreaks of diarrhea have been frequently attributed to these organisms. ${ }^{1}$ These often affect children and the immunosuppressed ${ }^{2,3}$ Many new diagnostic techniques have been reported to detect these pathogens in stool samples, including various concentration and staining methods. ${ }^{4,5,6}$ The diagnostic sensitivity of Iodine-Saline mount for Giardia and that of modified acid-fast staining for Cryptosporidia are often limited by the shedding of organisms intermittently or in low numbers. Sensitivity of these conventional staining methods also depends on the skill of the microscopist, and it is often highest when fulltime parasitology technologists are examining specimens. ${ }^{7}$

Journal of Evolution of Medical and Dental Sciences/Volume1/ Issue4/October- 2012 Page 285 
The majority of patients with cryptosporidiosis suffer with various degrees of diarrhea. In these symptomatic patients, the presence of large number of oocysts ensures that the diagnosis can be made by a number of techniques. However, there may be some situations e.g. some patients may be asymptomatic or exhibit fewer symptoms or when the number of oocysts present is very few. In these situations, the use of routine methods such as concentrations and modified acid-fast stains may be insufficient to demonstrate the presence of the parasite.

Giardia spp. cysts are shed sporadically and may vary in numbers. Examination of several sequential fecal specimens may not reveal infection with this parasite, particularly if the numbers are low. Co infection with both organisms have also been documented.8,9

Monoclonal antibody reagents with increased sensitivity offer an alternative method to the routine concentrations and stains, both of which may not reveal infections when few parasites are present. The purpose of the present study was to evaluate various methods for detection of Cryptosporidia and Giardia in fecal speimens.

To the best of our knowledge, this study is the first of its kind from North India in which we did comparison of different techniques for the identification of parasitic protozoa.

MATERIALS AND METHODS: Forty four human fecal specimens received from patients with diarrhea in the department of microbiology, Pt. B.D. Sharma PGIMS, Rohtak over a period of two months (3 $3^{\text {rd }}$ July to $3^{\text {rd }}$ September 2012) were analyzed retrospectively and processed in following manner:

\section{IODINE- SALINE WET MOUNT METHOD10}

Stool samples were collected in wide-mouthed disposable containers. With the help of applicator stick the stool sample was emulsified in a drop of saline on a clean dry slide and in a drop of Lugol's iodine on different slides. These were covered with coverslips and observed under the microscope at 400X magnification for the detection of ova and cysts.

\section{MODIFIED ACID FAST STAINING METHOD ${ }^{11}$ (MAF)}

Smears approximately 20 by $20 \mathrm{~mm}$ were prepared from samples. These were first stained with Carbol fuchsin (5 minutes) followed by decolorization with $1 \%$ Sulphuric acid ( 2 minutes), followed by counter staining with Methylene blue (1-2 minutes). All these smears were then examined with a $100 \mathrm{X}$ oil immersion objective, and the presence or absence of Cryptosporidial cysts was recorded.

\section{DIRECT FLUORESCENT MONOCLONAL ANTIBODY STAINING (DFA)}

The smears were prepared from the stool samples preserved in 10\% formalin and stained with the DFA Merifluor Cryptosporidia/Giardia kit (Meridian Diagnostics Inc., Cincinnati, Ohio) according to the manufacturer's instructions. This kit contained 50 treated slides along with detection reagent, Counter stain, 20X wash buffer, Positive control, Negative control, Mounting medium and transfer loops. A loopful of fecal material was spread over entire well. Positive and negative controls were put up in respective wells. Slides were air-dried for 30 minutes at room temperature. A drop of detection reagent followed by Counter stain was placed in each well. After incubating in humidified chamber for thirty minutes, slides were rinsed with a wash buffer. After removing excess buffer by tapping long edge of slides, a drop of mounting medium was 
added to each well and coverslip was applied. Each well was scanned thoroughly under fluorescent microscope (with a filter system for fluorescein isothiocyanate with following parameters: Excitation wavelength - 490-500; Barrier filter- 510-530) using 100-200X magnification. Cryptosporidium oocysts were round to slightly oval shaped, 2-6 $\mu \mathrm{m}$ in diameter and Giardia cysts were oval-shaped, 8-12 $\mu \mathrm{m}$ long. Both of these gave bright apple green fluorescence with DFA staining.

Statistical analysis was done by using Chi square test. SPSS version 19 was used.

\section{RESULTS:}

Among 44 patients, 30 were males and 14 were females. Out of these, 28 were children and 16 were adults. $71.43 \%$ females and $63.3 \%$ males were positive for C.parvum in this study. Neonates (75\%) were the most affected and least affected were adults (52.94\%).

In the case of Cryptosporidium oocysts, 29 specimens were positive by at least one method. Of these, 8 were positive by both the DFA and the modified acid-fast stains, 11 were positive by DFA alone, and 10 were positive only by the modified acid-fast stain [Table 1]. Overall, DFA staining significantly increased the detection of cryptosporidia ( $p$ value $=0.01)$. Of the two false-negative DFA results in the cryptosporidium group, these specimens showed no fluorescence at all. The lack of staining in these specimens could be due to sampling error.

$28.57 \%$ females and $6.7 \%$ males were positive for cysts of Giardia spp. in this study. Adults (23.5\%) were the most affected and least affected were neonates (5\%). Of the 44 specimens examined, 6 were positive for Giardia cysts by at least one method. Of these, 1 was positive by both DFA and routine methods, 4 were positive only by DFA, and 1 was positive only by the routine method [Table 2]. Thus the overall detection of Giardia cysts was increased significantly ( $\mathrm{p}$ value=0.01). The single false-negative DFA result was obtained in the Giardia group. It may be due to the sampling error.

During screening of stool samples, cysts of Entamoeba histolytica were detected in 3 samples and ova of Ascaris lumbricoides were detected in 1 sample. All these samples were negative for cysts of Cryptosporidium and Giardia.

Table 1. Comparison of DFA and MAF for Cryptosporidium oocysts

\begin{tabular}{|c|c|c|c|c|c|c|}
\hline Method & $\begin{array}{l}\text { No. of sp } \\
\text { Positive } \\
\text { Negative }\end{array}$ & gecimen & $\begin{array}{l}\text { Sensitivity } \\
(\%)\end{array}$ & $\begin{array}{c}\text { Specificity } \\
\text { (\%) }\end{array}$ & $\begin{array}{l}\text { Positive } \\
\text { predictive } \\
\text { value (\%) }\end{array}$ & $\begin{array}{l}\text { Negative } \\
\text { predictive } \\
\text { value (\%) }\end{array}$ \\
\hline DFA & 19 & 25 & $80 \%$ & $100 \%$ & $100 \%$ & $94.4 \%$ \\
\hline MAF & 10 & 34 & $40 \%$ & $91.7 \%$ & $80 \%$ & $64.7 \%$ \\
\hline
\end{tabular}


Table2. Comparison of DFA and Iodine-Saline wet mount method for Giardia cysts

\begin{tabular}{|c|c|c|c|c|c|}
\hline Method & $\begin{array}{l}\text { No. of } \\
\text { specimen } \\
(n=44) \\
\text { Positive } \\
\text { Negative }\end{array}$ & $\begin{array}{l}\text { Sensitivity } \\
\text { (\%) }\end{array}$ & $\begin{array}{c}\text { Specificity } \\
(\%)\end{array}$ & $\begin{array}{l}\text { Positive } \\
\text { predictive } \\
\text { value (\%) }\end{array}$ & $\begin{array}{l}\text { Negative } \\
\text { predictive } \\
\text { value (\%) }\end{array}$ \\
\hline DFA & 39 & $100 \%$ & $100 \%$ & $100 \%$ & $100 \%$ \\
\hline $\begin{array}{l}\text { Iodine-Saline } \\
\text { wet mount }\end{array}$ & 43 & $20 \%$ & $100 \%$ & $100 \%$ & $90.7 \%$ \\
\hline
\end{tabular}

DISCUSSION: Our results show that the DFA method, in addition to having excellent specificity, exhibits vastly improved sensitivity over those of the routine methods used. These findings support and supplement the initial experiences of others with this technique.12,13 Results of DFA in this study matches with that of Alles et al ${ }^{14}$ who reported sensitivity of $93 \%$, specificity$100 \%$, Positive predictive value-100\% and negative predictive value- $99.9 \%$ for Cryptosporidium parvum \& sensitivity-99.2\%, specificity-100\%, Positive predictive value-100\% and negative predictive value- $99.96 \%$ for Giardia spp. Zimmerman et al ${ }^{15}$ also reported $100 \%$ sensitivity and $99.8 \%$ specificity of DFA. $96.4 \%$ sensitivity of DFA was reported by Kehl et al ${ }^{16}$ who observed that DFA test detected 53 out of 55 positive fecal samples for these parasitic pathogens. Immunofluorescence assay for antigen detection of Cryptosporidium parvum offers the highest combination of sensitivity and specificity and is considered the gold standard by many laboratories. The sensitivities and specificities of various commercially available kits for antigen detection range from $66.3 \%$ to $100 \%$ and $93 \%$ to $100 \%$ respectively. ${ }^{17}$

For the diagnosis of cryptosporidiosis Kashyap B. et al ${ }^{18}$ found that Kinyoun staining gave a sensitivity of $80 \%$ and a specificity of $100 \%$. The positive predictive value (PPV) and the negative predictive value (NPV) of Kinyoun staining were 100 and 96.5\%, respectively. While in our study, the sensitivity, specificity, Positive predictive value \& Negative predictive value for MAF staining was $40 \%, 91.7 \%, 80 \%, 64.7 \%$ respectively.

Barua P. et al ${ }^{19}$ found Modified Z-N technique to be efficacious method for routine screening of fecal specimens for Cryptosporidium spp in comparison with ELISA.

The 9 fecal specimens which came to be positive by DFA test, but not detected by the conventional acid fast stain, can be considered in fact true positive specimens with low intensity, based on reports by Kehl et al ${ }^{16}$ who found that carbol fuchsin failed to stain some of the oocysts in fecal specimens and that DFA is more specific than the acid fast staining. ${ }^{12,20}$ The laboratory diagnosis of both Cryptosporidiosis and Giardiasis from fecal specimens can be improved upon by increasing use of DFA technique. Its advantages over wet mount and staining method include faster detection time and need for comparatively less skilled staff. Moreover, C. parvum and G. lamblia can be detected in the same sample by a single test. However, the DFA method (Both Kit \& Fluorescent microscope) is considerably more expensive than other two methods, and this probably is limiting factor in its use in the routine stool examination. 


\section{BIBLIOGRAPHY}

1. G H Tee, A H Moody, A Hunt Cooke, P L Chiodini. Comparison of techniques for detecting antigens of Giardia lamblia and Cryptosporidium parvum in faeces. Jr Clin Pathol 1993;46:555-558.

2. Current, W.L., L. S. Garcia. Cryptosporidiosis. Clin Microbiol Rev.1991;4:325-358.

3. Farthing M.J. Diarrhoeal disease: current concepts and future challenges. Pathogenesis of giardiasis. Trans R Soc Trop Med Hyg.1993;87 Suppl. 3:17-21.

4. Baxby D., Blundell N. Sensitive, rapid, simple methods for detecting Cryptosporidium in faeces. Lancet.1983; ii:1149.

5. Garcia, L. S., D. A. Bruckner, T. C. Brewer, R. Y. Shimizu. Techniques for the recovery and identification of Cryptosporidium oocysts from stool specimens. J Clin Microbiol.1983;18:185-190.

6. Arora DR, Arora B. AIDS-Associated Parasitic Diarrhoea. Ind J Med Microbiol.2009;27:185-90

7. Mohr, E., Mohr,I. Statistical analysis of the incidence of positives in the examination of parasitological specimens. J Clin Microbiol.1992;30:1572-4.

8. \okipii L, Pohjola S, Lokipii AM. Cryptosporidiosis associated with traveling and giardiasis. Gastroenterology.1985;89:838-842.

9. Skeels R.M., Sokolow R., Hubbard V.C., Foster R.L. Screening for Coinfection with Cryptosporidium and Giardia in Oregon Public Health Clinic Patients. American Journal of Public Health,1986;76:270-273.

10. Arora DR, Arora B. Medical Parasitology: $2^{\text {nd }}$ ed. CBS Publishers and Distributors; New Delhi, Bangalore, India: 2004. p. 235.

11. Koneman E.W., Allen S.D., Janda W.M., Schreckenberger P.C., Winn Jr. W.C. Koneman's Color Atlas and Textbook of Diagnostic Microbiology. Lippincott-Raven Publishers, $6^{\text {th }}$ edition. Philadelphia:2006. p.1075-1076.

12. Garcia S.L., Shum A.C., Bruckner A.D. Evaluation of a New Monoclonal Antibody Combination Reagent for Direct Fluorescence Detection of Giardia Cysts and Cryptosporidium Oocysts in Human Fecal Specimens. J Clin Microbiol.1992;30:32553257.

13. Xiao L., Herd. R.P. Quantitation of Giardia cysts and Cryptosporidium oocysts in fecal samples by direct immunofluorescence assay. J Clin Microbiol.1993;31:2944-2946.

14. Alles A.J., Waldron M.A.,Sierra L., Mattia A.R. Prospective Comparison of Direct Immunofluorescence and Conventional Staining Methods for Detection of Giardia and Cryptosporidium spp. in Human Fecal Specimens. J.Clin Microbiol.1995;33:1632-1634.

15. Zimmerman S.K. , Needham C.A. Comparison of Conventional Stool Concentration and Preserved- Smear Methods with Merifluor Cryptosporidium/Giardia Direct Immunofluorescence Assay and ProSpecT Giardia EZ Microplate Assay for Detection of Giardia lamblia. J Clin Microbiol..1995;33:1942-1943.

16. Kehl K.S., Cicirello H, Havens PL. Comparison of four different methods for detection of Cryptosporidium species. J Clin Microbiol.1995;33:416-418.

17. Mehta P. Laboratory diagnosis of Cryptosoridiosis.Ind J Med Microbiol.2002;48:217.

18. Kashyap B., Sinha S., Das S., Rustagi N., Jhamb R. Efficiency of diagnostic methods for correlation between prevalence of enteric protozoan parasites and HIV/AIDS status-an experience of a tertiary care hospital in East Delhi. J Parasit Dis.2010 ;34:63-67. 
19. Barua P., Hazarika NK, Barua N, Rasul E.,Laskar N. Microscopy for Cryptosporidiosis Screening in Remote Areas. Indian J Med Microbiol.2008;26:203-204.

20. Weber R, Bryan RT, Bishop HS, Wahlquist S.P., Sullivan J.J., Juranek D.D. et al. Threshold of detection of Cryptosporidium oocysts in human stool specimens for low sensitivity of current diagnostic methods. J Clin Microbiol.1991;29:1323-7.

Journal of Evolution of Medical and Dental Sciences/Volume1/ Issue4/October- 2012 Page 290 